\title{
Investigation of bifid mandibular canal frequency with cone beam computed tomography in a Turkish population
}

\author{
Gözde Serindere $^{1}$, Kaan Gündüz ${ }^{2}$, Elif Bulut ${ }^{3}$ \\ ${ }^{1}$ Department of Dentomaxillofacial Radiology, Faculty of Dentistry, Mustafa Kemal University, Hatay, Turkey \\ ${ }^{2}$ Department of Dentomaxillofacial Radiology, Faculty of Dentistry, Ondokuz Mayıs University, Samsun, Turkey \\ ${ }^{3}$ Department of Business Administration, Faculty of Economics and Administrative Sciences, Ondokuz Mayıs University, Samsun, Turkey
}

\begin{abstract}
Objectives: It is important to know anatomic location and variations of the mandibular canal (MC) for surgical treatment on mandible such as implant operations, impacted molar tooth extraction and sagittal split ramus osteotomy. The purpose of our study is to determine the configuration and incidence of bifid mandibular canal (BMC) using cone beam computed tomography (CBCT).

Methods: CBCT scans of 2000 patients were retrospectively analysed. Age and gender of the patients who were included in this study were recorded. BMC was subdivided, frequency was determined. Measurements of mean lengths, superior and inferior angles were performed. The all measurements were performed by one observer in 3 times at intervals of one week to confirm intra-observer reliability. SPSS 21 (Statistical Package for Social Science 21) was used for statistical analysis. It was benefited from Chi-square test to investigate qualitative observation and from $T$ test and one-way analysis of variance for investigation of quantative observation. Differences were considered significant at $p<0.05$.
\end{abstract}

Results: 1122 of 2000 patients (56.1\%) were females and 878 of 2000 patients (43.9\%) were males. BMC was observed in 61 of 2000 patients (3.05\%). Because location of MC is bilateral, 122 sides in 61 patients were studied. BMC was observed in 65 of 122 sides (53.3\%). In 39 of 65 sides (60\%), BMC was observed in males, in 26 of 65 (40\%) sides, BMC was observed in females.

Conclusion: CBCT provides important informations about MC imaging and evaluation of variations. Evaluation of MC variations frequency and informing to surgeon in surgical procedures on mandible provides advantages for successful operations.

Keywords: anatomy; bifurcation; cone beam computed tomography; mandibular canal

Anatomy 2017;11(1):30-36 C2017 Turkish Society of Anatomy and Clinical Anatomy (TSACA)

\section{Introduction}

The mandibular canal (MC) or the inferior alveolar canal transmits the inferior alveolar nerve, associated vessels and a branch of the third division of the trigeminal nerve. MC is between mandibular foramen and mental foramen. The inferior alveolar nerve is subdivided to the terminal dental and incisive branches to innerve the teeth and adjacent anatomical structures. ${ }^{[1]}$

The term of 'bifid' is a Latin word that means a cleft into two parts or branches. Bifid mandibular canal (BMC) originates at the mandibular foramen. These bifid canals may include a neurovascular bundle. ${ }^{[2]}$
Panoramic radiography, CT and cone beam CT (CBCT) can be used to determine the prevalence of BMC. ${ }^{[3]}$ In radiography, MC is seen as dark and linear shadow with thin radiopaque superior and inferior borders. The borders of MC are sometimes seen partially or not at all. The width of MC varies from patient to another patient. But it is usually constant anterior to the third molar area. ${ }^{[4]}$

The opposing side of mandible, the soft palate, the pharyngeal airway and the uvula cause ghost shadows. Therefore, the location of the MC is difficult in panoramic radiographs. ${ }^{[4]}$ Rouas et al. ${ }^{[5]}$ also reported that panoramic radiography has limitations to diagnose the BMC and 
suggested CBCT that has slightly more radiation dose than panoramic radiography and far less than CT. Orhan et al. ${ }^{[3]}$ found more $\mathrm{BMC}$ compared to earlier $\mathrm{t}$ studies using panoramic radiography and suggested that $\mathrm{CBCT}$ is very useful modality to detect the BMC. CBCT imaging technique produces submilimeter resolution images of maxillofacial region with lower doses and costs compared to $\mathrm{CT}^{\left[{ }^{[4]}\right.}$

In addition, patients with bifid canals are at greater risk of inadequate anesthesia or difficulties with jaw surgery. ${ }^{[4]}$ As a result, it is extremely important to know the anatomy and variations of $\mathrm{MC}$ to reduce the damage of mandibular nerve bundle in intraoral operations during lower third molar surgery, implant operations, mandibular osteotomy, and mandibular fracture. Today, implant operations have increased, and therefore $\mathrm{BMC}$ has become more important. For this reason, our study aimed to determine the prevalence and localisation of BMC in CBCT scans.

\section{Materials and Methods}

After the statement regarding Ethics Committee approval for the study (Approval number B.30.2.ODM.0.20.08/ 1088). The patients were 18 to 75 years old in age (mean age: 45.78 for males and 42.5 for females) and were referred to Ondokuz Mayıs University Dentomaxillofacial Radiology Department between the years of 2013 and 2015 with various reasons such as missing teeth, decay, orthodontic treatment etc. CBCT images performed for evaluation of 2000 patients were retrospectively analysed (878 males, 1122 females; mean age: 44.49)

Inclusion criteria for patient selection were the age of the patients (18 to 75 ) and sufficient quality of CBCT scans to diagnose. Patients with pathologic lesions in the posterior region of mandible were excluded from the study.

Sirona, Galileos (Sirona Dental Systems, Bensheim, Germany) (98 kV, $25 \mathrm{mAs}$ ) was used to obtain the images. Image analysis were done by using Sidexis (Sirona, Bensheim, Germany) program. The dedector type of device was Image Intensifier (Siemens, Munich, Germany) with 4096 brightness value. FOV size was $15 \times 15 \times 15 \mathrm{~cm}^{3}$. Voxels were isotropic and $0.25 \times 0.25 \times 0.25 \mathrm{~mm}^{3}$. Half value layer was $3.9 \mathrm{~mm} \mathrm{Al}$. Cone beam angle was approximately $24^{\circ}$.

All CBCT images were acquired properly. After reconstruction, all images in axial, tangential and crosssection, reconstructed panoramic images and $3 \mathrm{D}$ images were investigated (Figure 1). All evaluations and measurements were performed on a 27 inch monitor with a resolution of $2560 \times 1440$ at 10 bit.

All CBCT images were evaluated by a single observer. Detected BFCs were controlled by an dentomaxillofacial radiologists who had more than 10 years of experience. Intra-class correlation was calculated for quantitative datas. Cohen's kappa values were calculated for cat-

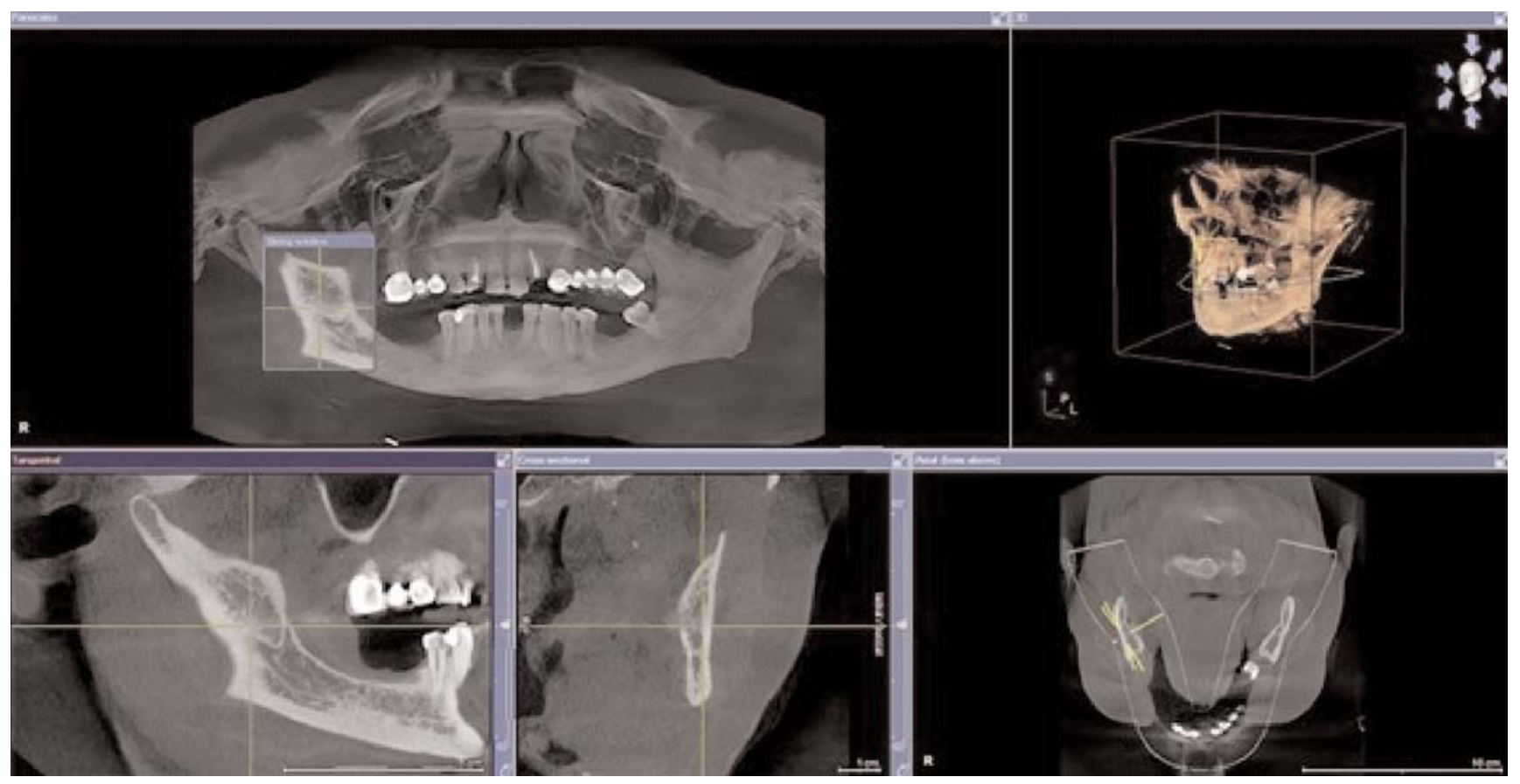

Figure 1. Reconstructed panorama, axial, tangential, cross sectional and 3D images. [Color figure can be viewed in the online issue, which is available at www.anatomy.org.tr] 
egoric datas. Intra-observer reliability was found as 0.317 suggesting that the low kappa values were a result of infrequency of BMCs in the study sample because of the high numbers of evaluated patients.

The length and angle of BMCs were measured either in tangential and panoramic reconstructed CBCT images using the own software of CBCT system. The length of BMCs was measured between starting point of seperation from the main canal and the tip point. The superior and inferior angle measurements were also performed. In the superior angle measurements, the angle between the main canal and superior wall of BMCs were measured. For inferior angle measurements, the angle between the main canal and inferior wall of BMCs was measured (Figure 2). All measurements were performed by one observer for three times at intervals of one week to confirm intra-observer reliability. The mean values of measurements were analysed.

According to Naitoh et al. ${ }^{[6]}$ classification, BMCs were divided into four groups considering location. These were forward, retromolar, dental and buccolingual canals

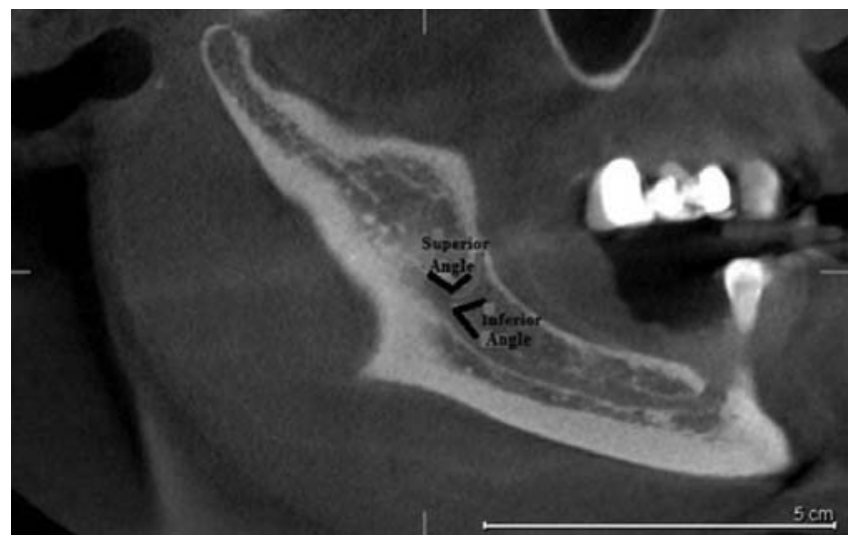

Figure 2. Sagittal scan showing superior and inferior angle measurement of BMC.

(Figure 3). Forward canals were subdivided into with confluence and without confluence. Dental canals were subdivided into first, second and third molar canals according to the region of seperation from the main canal. Additionally,

Figure 3. (a) Sagittal view of bifid retromolar canal. (b) Sagittal view of the third molar type dental canal. (c) Sagittal view of forward canal. (d) Axial view of the buccolingual canal.
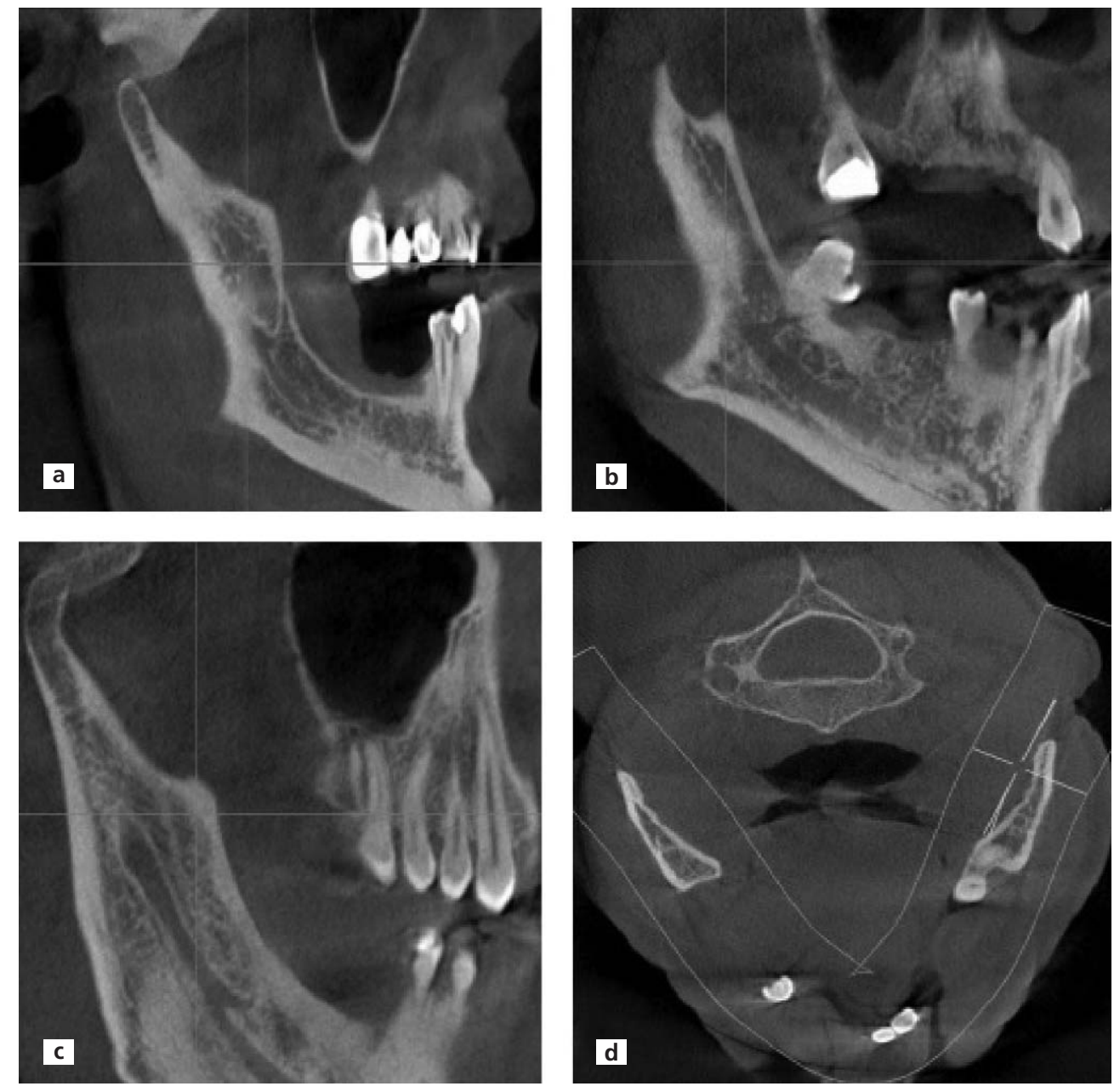
the buccolingual canals were subdivided into buccal or lingual canal considering location of bifid canal.

IBM SPSS (Statistical Package for the Social Sciences, version 21; IBM, Chicago, IL, USA) software was used for statistical analysis. There were qualitative and quantitative observations in our study data, so we used Chi-square test to investigate qualitative observation and from t-test and one-way analysis of variance for investigation of quantative observation. Differences were considered significant at $\mathrm{p}<0.05$.

\section{Results}

Bifid mandibular canals were observed in 61 of 2000 patients $(3.05 \%)$. Because location of mandibular canal is bilateral, 122 sides in 61 patients ( 37 men and 24 women) were studied. BMC were observed in 65 of 122 sides $(53.3 \%)$.The relationship between gender and canal type are showed in Table 1. In 39 of 65 sides (60\%), BMCs were observed in males. In 26 of 65 (40\%) sides, BMCs were observed in females. No statistically significant difference was found between gender and type of BMCs $(\mathrm{p}=0.345>0.05)$. BMCs were frequently found in the fourth decade. According to relationship among age groups and canal types, retromolar canals were frequently found in the fifth decade, forward canals in the fourth decade, dental canals in the third and fourth decade equally, and two buccolingual canals in the second and fifth decade. The obtained data are shown in Table 2 . Difference between age and type of BMCs was evaluated with using chi-square test. No statistically significant differences were found between age and type of BMCs $(\mathrm{p}>0.05)$.

The number of different groups of BMCs are shown in Table 3. The most fequently observed type was the retromolar canal ( $\mathrm{n}=39,18$ right sides, 21 left sides) followed by the dental canal ( $\mathrm{n}=14,8$ right sides, 6 left sides), forward canal ( $\mathrm{n}=10,5$ right sides, 5 left sides) and buccolingual canal ( $\mathrm{n}=2$, one right side, the other one left side). Of the 10 forward canals, 9 of them occured without confluence
Table 1

Relationship between gender and type of BMC.

\begin{tabular}{lccccc}
\hline \multirow{4}{*}{ Gender } & \multicolumn{5}{c}{ Types of BMC } \\
\cline { 2 - 5 } & $\begin{array}{c}\text { Retromolar } \\
\text { canal }\end{array}$ & $\begin{array}{c}\text { Forward } \\
\text { canal }\end{array}$ & $\begin{array}{c}\text { Dental } \\
\text { canal }\end{array}$ & $\begin{array}{c}\text { Buccolingual } \\
\text { canal }\end{array}$ & Total \\
\hline Male & 25 & 4 & 8 & 2 & 39 \\
Female & 14 & 6 & 6 & 0 & 26 \\
Total & 39 & 10 & 14 & 2 & 65 \\
\hline
\end{tabular}

Table 2

Distribution of types of BMC according to age groups.

\begin{tabular}{lccccc}
\hline Decade & Retromolar & Forward & Dental & Buccolingual & Total \\
\hline 1 & - & - & 1 & - & 1 \\
2 & 5 & - & 3 & 1 & 9 \\
3 & 7 & 1 & 4 & - & 12 \\
4 & 8 & 5 & 4 & - & 17 \\
5 & 12 & 2 & 1 & 1 & 16 \\
6 & 4 & 1 & 1 & - & 6 \\
Total & 36 & 9 & 14 & 2 & 61 \\
\hline
\end{tabular}

Table 3

The numbers of different groups of bifid canals according to gender and types.

\begin{tabular}{llccccc}
\hline \multirow{2}{*}{ Gender } & BMC & \multicolumn{6}{c}{ Types of BMCs } \\
\cline { 3 - 7 } & location & Retromolar & Forward & Dental & Buccolingual & Total \\
\hline \multirow{2}{*}{ Male } & Left & 11 & 3 & 3 & 1 & 18 \\
& Right & 14 & 1 & 5 & 1 & 21 \\
& Total & 25 & 4 & 8 & 2 & 39 \\
\hline \multirow{2}{*}{ Female } & Left & 10 & 2 & 3 & & 15 \\
& Right & 4 & 4 & 3 & & 11 \\
& Total & 14 & 6 & 6 & & 26 \\
\hline
\end{tabular}

and one of them with confluence. Of the 14 dental canals, one of them extended to the root apex of the first molar, one of them to the second molar, and 12 to the third molar. All two buccolingual canals were positioned in buccal side. The distribution of canal types according to gender and location in detail are shown in Table 4. There was

Table 4

The distribution of canal types according to gender and location.

\begin{tabular}{|c|c|c|c|c|c|c|c|c|c|}
\hline \multirow[t]{2}{*}{ Gender } & & \multirow[t]{2}{*}{ Retromolar } & \multicolumn{2}{|l|}{ Forward } & \multicolumn{3}{|c|}{ Dental } & \multirow[t]{2}{*}{ Buccolingual } & \multirow[t]{2}{*}{ Total } \\
\hline & & & Confluence present & Absent & 1st molar & 2nd molar & 3rd molar & & \\
\hline \multirow[t]{3}{*}{ Male } & Left & $11(16.92 \%)$ & $3(4.62 \%)$ & - & - & - & $3(4.62 \%)$ & $1(1.54 \%)$ & $18(27.69 \%)$ \\
\hline & Right & $14(21.54 \%)$ & - & $1(1.54 \%)$ & $1(1.54 \%)$ & $1(1.54 \%)$ & $3(4.62 \%)$ & $1(1.54 \%)$ & $21(32.31 \%)$ \\
\hline & Total & $25(38.46 \%)$ & $3(4.62)$ & $1(1.54)$ & $1(1.54)$ & $1(1.54)$ & $6(9.23)$ & $2(3.08 \%)$ & $39(60 \%)$ \\
\hline \multirow[t]{2}{*}{ Female } & Left & $10(15.38 \%)$ & $2(3.08 \%)$ & - & - & - & $3(4.62 \%)$ & $15(23.07 \%)$ & \\
\hline & Right & $4(6.15 \%)$ & $4(6.15)$ & - & - & - & $3(4.62 \%)$ & $11(16.92 \%)$ & \\
\hline Total & & $14(21.53 \%)$ & $6(9.23 \%)$ & - & - & - & $6(9.23 \%)$ & $26(40 \%)$ & \\
\hline
\end{tabular}


no statiscally significant differences between canal type and canal localisation ( $\mathrm{p}>0.05$ ).

The mean length of BMCs was $12.78 \mathrm{~mm}$ on the right side and $11.6 \mathrm{~mm}$ on the left side. According to the types BMCs, the mean length of bifid retromolar canal was $11.57 \mathrm{~mm}$ (right side $12.4 \mathrm{~mm}$, left side $10.8 \mathrm{~mm}$ ), the mean length of dental canal was $12.9 \mathrm{~mm}$ (right side 14.3 $\mathrm{mm}$, left side $11.03 \mathrm{~mm}$ ), $15.2 \mathrm{~mm}$ for forward canal (right side $15.08 \mathrm{~mm}$, left side $15.3 \mathrm{~mm}$ ), and $2.18 \mathrm{~mm}$ for buccolingual canal (right side $2.05 \mathrm{~mm}$, left side $2.32 \mathrm{~mm}$ ). Statistically significant differences were found for length between the right and left sides and location of the BMCs with using Wilcoxon signed rank test. Differences between type and length of BMCs were evaluated with using one-way analysis of variance test and statistically significant differences were found between type and length of BMCs $(\mathrm{p}<0.05)$.

Mean superior angle was $133.3^{\circ}$ on the right side and $151^{\circ}$ on the left side. Mean inferior angles was $44.9^{\circ}$ on the right side and $44.5^{\circ}$ on the left side. According to the canal types, mean right superior angles of retromolar, dental and forward canals were $127.4^{\circ}, 141.1^{\circ}$ and $136.5^{\circ}$, respectively; mean right inferior angles were $53.4^{\circ}, 51.3^{\circ}$ and $12.4^{\circ}$, respectively. Mean left superior angles of retromolar, dental and forward canals were $149.4^{\circ}, 145.5^{\circ}$ and $163.1^{\circ}$, respectively. Mean left inferior angles were $46.2^{\circ}, 62.5^{\circ}$ and $13.7^{\circ}$ with the same order. No statistically significant differences were found between types of BMCs and superior angles with using ANOVA test, but statistically significant differences were found between types of BMC types and inferior angles $(\mathrm{p}<0.05)$.

\section{Discussion}

There are a large number of studies on the anatomical location and configuration of BMC using panoramic radiography. These studies reported BMC ranging from 0.08 to $0.95 \% \cdot{ }^{[1,2,7,8]}$ Stıdies using CBCT are less than studies using panoramic radiography. CBCT studies reported the incidence of BMCs ranging from $15.6 \%$ to $66.5 \%$. ${ }^{[3,6,9]}$ Kuribayashi et al. ${ }^{[9]}$ reported the incidence as $15.6 \%$, Naitoh et al. ${ }^{[6]} 65 \%$, and Orhan et al. ${ }^{[3]} 66.5 \%$. In our study, the incidence of $\mathrm{BMC}$ was $3.05 \%$ which was lower than the number reported by earlier CBCT studies. But it is possible to see that the incidence of $\mathrm{BMC}$ in the studies using CBCT was higher than that in the studies using panoramic radiography, indicating that panoramic radiography technique was insufficient to determine all BMCs. Due to the importance of $\mathrm{BMC}$ for surgical procedure, the limitations of panoramic radiography technique to diagnose $\mathrm{BMC}$ must be considered. However, panoramic radiography was suggested to diagnose BMC due to high cost and high radiation dose of computed tomography. ${ }^{[10]}$
In our study, we found BMC more frequently in males than in females. However, in some studies, the incidence of BMC was higher in females. ${ }^{[1,8]}$ In our study, the mean age was 45.78 for males and 42.5 for females. Orhan et al. ${ }^{[3]}$ reported the mean age of their subjects as 36.7 (range: 17 to 83 ) years

Orhan et al. ${ }^{[3]}$ found the most frequently observed type of BMC as the forward canal $(29.8 \%)$ and the less observed type the dental canal (8.3\%). In our study, the most frequently observed type was retromolar canal and the less observed type was buccolingual canal. Naitoh et al. ${ }^{[9]}$ found similar results with Orhan et al. ${ }^{[3]}$ and reported that the most frequently observed type was forward canal $(44.3 \%)$. But, they reported that the less observed type was buccolingual canal (1.6\%), similar to our study.

Both the study of Naitoh et al. ${ }^{[6]}$ and of Orhan et al. ${ }^{[3]}$ reported that the most frequently observed type of dental canals as the third molar type, and of forward canals the without confluence type. $55.3 \%$ and $7 \%$ and in the study of Naitoh et al. ${ }^{[6]}$ as compared to $18.4 \%$ and $3.8 \%$ in the study of Orhan et al. ${ }^{[3]}$ These results are similar to the results of our study.

Orhan et al. ${ }^{[3]}$ reported the mean lenght of BMC as $13.6 \mathrm{~mm}$ on the right side and $14.1 \mathrm{~mm}$ on the left side. In present study, the mean length of BMC was $12.7 \mathrm{~mm}$ on the right side and $11.6 \mathrm{~mm}$ on the left side. According to subdivided types, in the study of Orhan et al. ${ }^{[3]}$ the mean length of bifid retromolar canal was $13.5 \mathrm{~mm}(13.4 \mathrm{~mm}$ on the right side; $13.6 \mathrm{~mm}$ on the left side), dental canal was $8.3 \mathrm{~mm}$ ( $8.1 \mathrm{~mm}$ on the right side; $8.4 \mathrm{~mm}$ on the left side), forward canal was $20.1 \mathrm{~mm}$ (19.3 mm on the right side; 21 $\mathrm{mm}$ on the left side) and the mean diameter of buccolingual canals was $3.8 \mathrm{~mm}(3.4 \mathrm{~mm}$ on the right side; $4.1 \mathrm{~mm}$ on the left side). In our study, the mean length of bifid retromolar and forward canals and the mean diameter of buccolingual canals were found less, but the mean length of dental canal was found more than the study of Orhan et al. ${ }^{[3]}$ The mean superior angle of BMC was found 139 on the right side and 141 on the left side, while the mean inferior angle was found 38 on the right side and 32 on the left side. ${ }^{[3]}$ In our study, mean right superior angle was lower, but the other values were higher than the study of Orhan et al. ${ }^{[3]}$ who reported that no statistically differences were found in either lenghts or angles between the right and left sides and for gender. However, in our study, statistically significant differences were found between the mean inferior angles and canal types between the right and left sides and for gender.

Sanchis et al. ${ }^{[1]}$ evaluated 2012 panoramic radiographs (736 males, 1276 females; mean age 40.4) and found seven cases $(0.35 \%)$ of BMC. Four of the seven cases 
were found bilaterally, the rest was found unilaterally, and the all BMCs were found in females. In our study, bilateral BMCs were found in four of 61 patients.

Kuribayashi et al. ${ }^{[9]}$ evaluated 252 patients (94 males, 158 females; mean age: 33 years) and reported the incidence of $\mathrm{BMC}$ as $15.6 \%$ and the mean length of $\mathrm{BMC}$ as $1.68 \mathrm{~mm}$. In our study, the incidence and mean length of $\mathrm{BMCs}$ and the mean age of patients were found higher.

BMCs, especially when there are two mandibular foramina, anesthesia of the inferior alveolar nerve may be inadequate. If there is only soft tissue anaesthesia around the injection site in the patient, but not of the ipsilateral lip or chin, it should be considered about a problem with local anesthesia technique that is likely to be the cause of the failure. While if there is soft tissue anaesthesia of the lips and chin but not the teeth, then anatomical variation should be considered. ${ }^{[11,12]}$ Unsuccessful anesthesia is the most common problem in the patients with BMC. So, The GowGates or Akinosi techniques are preferrable methods of blocking the inferior alveolar nerve in the cases of BMC..$^{[10]}$

If there is a second neurovascular bundle within the BMC, complications such as traumatic neuroma, paraesthesia and bleeding may occur because of failure to diagnose this anomaly. Because of a second neurovascular bundle, other surgical procedures such as mandibular osteotomy become more complex. If alveolar bone resorbs to the proximity of the mental foramen, because of the pressure on the neurovascular bundle, patients who use mandibular prostheses may be uncomfortable. ${ }^{[11]}$

Three dimensional radiography techniques provide more exact position of the canal, especially about the buccolingual position of the canal. ${ }^{[13]}$ Peker et al. ${ }^{[14]} \mathrm{com}-$ pared panoramic radiography, conventional (cross-sectional) tomography and CT for the location of MC before implant operation in the posterior mandible. MC couldn't be localized in $19.4 \%$ of panoramic radiographs and in $13.9 \%$ of conventional tomograms but it could be found in almost all CT images.

In another study by Angelopoulos et al., ${ }^{[15]}$ digital panoramic radiography and CBCT was compared for observation of the MC before dental implant operation. All studies found MC at higher rate in CBCT. Statistically significant differences were found between panoramic radiography and CBCT.

Tantanapornkul et al. ${ }^{[16]}$ compared panoramic radiography and CBCT in detection of the relationship between the $\mathrm{MC}$ and impacted third molars. During the extraction of the third molar, the sensitivity and specificity were found as $93 \%$ and $77 \%$, respectively, for CBCT in visualisation of damage of the inferior alveolar nerve. They reported that CBCT was superior to panoramic images in both sensitivity and specificity.

In the study of Kim et al., ${ }^{[17]}$ panoramic radiographs from 1000 dental patients and 40 dry mandibles were examined for the presence of BMC. According to their study, in four cases, the panoramic radiographs showed indicated double MCs, suggesting that the prevalence of BMCs in Koreans was $0.038 \%$. Among the panoramic radiographs belonging to the dry mandibles, only one case appeared to have a BMC. Later, a CBCT scan was performed at the second molar region and the mental foramen region to determine if these canals were real BMCs. The BMC was found in the second molar area with CBCT. Two canals were detected by radio-opaque lines; one upper canal was circular in outline, whereas the other lower canal was elliptical. However, it was reported that one canal was detected in mental foramen area.

Kalender et al ${ }^{[18]}$ evaluated CBCT scans of 386 regions in 193 patients (92 males, 101 females) referred to their clinic during a 2-year period were analyzed retrospectively. Accessory mental foramina were most commonly located anteroinferior to the mental foramen, followed by locations posteroinferior to the mental foramen. Bilateral accessory mental foramina anteroinferior to the mental foramen were observed in a 24-year-old male patient. Three accessory mental foramina located anteroinferior, inferior, and posterosuperior to the mental foramen were observed in a 19 -year-old female patient. In a 28 -year-old male patient exhibited two accessory foramina inferior to the mental foramen on the left side were found. They reported that one $\mathrm{MC}$ was found on each side in all of their patients. Accessory mental foramen was important due to continuity with mandibular canal especially about injury to the neurovascular bundles and performing other invasive procedures. ${ }^{[18]}$ In our study, the incidence of BMC was found at higher rates compared to studies using panoramic radiography, but less than other studies using CBCT.

As a result, the position of mental foramen and evaluation of $\mathrm{MC}$ variation frequency by dentomaxillofacial radiologists and informing these to the surgeon in mandibular surgical procedures is very important for successful operations and the patient's comfort, and to prevent complications. BMC is an uncommon anatomical variation, so dentists may not have adequate experience to diagnose this variations. Especially in procedures that are frequently performed such as third molar extraction and implant surgery in molar region, diagnosing this variation becomes more important. With the use of CBCT in dentistry, BMC has been found more frequently. Therefore, the right radiographic technique and development in techniques should be considered for assessment of MC 
variations and for diagnosing and treatment. Further studies on MC variations will bring innovations to points to be taken into consideration in the mandibular molar region.

\section{References}

1. Sanchis JM, Peñarrocha M, Soler F. Bifid mandibular canal. J Oral Maxillofac Surg 2003;61:422-4.

2. Langlais RP, Broadus R, Glass BJ. Bifid mandibular canals in panoramic radiographs. J Am Dent Assoc 1985;110:923-6.

3. Orhan K, Aksoy S, Bilecenoglu B, Sakul BU, Paksoy CS. Evaluation of bifid mandibular canals with cone-beam computed tomography in a Turkish adult population: a retrospective study. Surg Radiol Anat 2010;33:501-7.

4. White SC, Pharoah MJ. Oral radiology: principles and interpretation. St. Louis (MO): Mosby Elsevier; 2009. p. 175-244.

5. Rouas P, Nancy J, Bar D. Identification of double mandibular canals: literature review and three case reports with CT scans and cone beam CT. Dentomaxillofac Radiol 2007;36:34-8.

6. Naitoh M, Hiraiwa Y, Aimiya H, Ariji E. Observation of bifid mandibular canal using cone-beam computerized tomography. Int J Oral Maxillofac Implants 2009;24:155-9

7. Grover PS, Lorton L. Bifid mandibular nerve as a possible cause of inadequate anesthesia in the mandible. J Oral Maxillofac Surg 1983;41:177-9.

8. Nortjé CJ, Farman AG, Grotepass FW. Variations in the normal anatomy of the inferior dental (mandibular) canal: a retrospective study of panoramic radiographs from 3612 routine dental patients. Br J Oral Surg 1977;15:55-63.

9. Kuribayashi A, Watanabe H, Imaizumi A, Tantanapornkul W, Katakami K, Kurabayashi T. Bifid mandibular canals: cone beam computed tomography evaluation. Dentomaxillofac Radiol 2010;39:235-9.
10. Auluck A, Pai KM, Shetty C. Pseudo bifid mandibular canal. Dentomaxillofac Radiol 2005;34:387-8.

11. Claeys V, Wackens G. Bifid mandibular canal: literature review and case report. Dentomaxillofac Radiol 2005;34:55-8.

12. Wadhwani P, Mathur RM, Kohli M, Sahu R. Mandibular canal variant: a case report. J Oral Pathol Med 2008;37:122-4.

13. Mizbah K, Gerlach N, Maal TJ, Bergé SJ, Meijer GJ. The clinical relevance of bifid and trifid mandibular canals. Oral Maxillofac Surg 2011;16:147-51.

14. Peker I, Alkurt Toraman M, Mihcioglu T. The use of 3 different imaging methods for the localization of the mandibular canal in dental implant planning. Int J Oral Maxillofac Implants 2008;23: 463-70.

15. Angelopoulos C, Thomas S, Hechler S, Parissis N, Hlavacek M. Comparison between digital panoramic radiography and cone-beam computed tomography for the identification of the mandibular canal as part of presurgical dental implant assessment. J Oral Maxillofac Surg 2008;66:2130-5.

16. Tantanapornkul W, Okouchi K, Fujiwara Y, Yamashiro M, Maruoka Y, Ohbayashi N, Kurabayashi T. A comparative study of cone-beam computed tomography and conventional panoramic radiography in assessing the topographic relationship between the mandibular canal and impacted third molars. Oral Surg Oral Med Oral Pathol Oral Radiol Endod 2007;103:253-9.

17. Kim MS, Yoon SJ, Park HW, Kang JH, Yang SY, Moon YH, Jung NR, Yoo HI, Oh WM, Kim SH. A false presence of bifid mandibular canals in panoramic radiographs. Dentomaxillofac Radiol 2011;40:434-8.

18. Kalender A, Orhan K, Aksoy U. Evaluation of the mental foramen and accessory mental foramen in Turkish patients using cone-beam computed tomography images reconstructed from a volumetric rendering program. Clin Anat 2012;25:584-92.

Correspondence to: Gözde Serindere, PhD

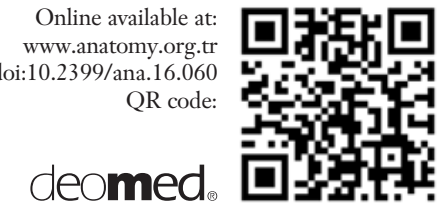
Department of Dentomaxillofacial Radiology, Faculty of Dentistry, Mustafa Kemal University, Hatay, Turkey Phone: +90 5058659063 e-mail: gozdeserindere@mku.edu.tr

Conflict of interest statement: No conflicts declared.

This is an open access article distributed under the terms of the Creative Commons Attribution-NonCommercial-NoDerivs 3.0 Unported (CC BY-NCND3.0) Licence (http://creativecommons.org/licenses/by-nc-nd/3.0/) which permits unrestricted noncommercial use, distribution, and reproduction in any medium, provided the original work is properly cited. Please cite this article as: Serindere G, Gündüz K, Bulut E. Investigation of bifid mandibular canal frequency with cone beam computed tomography in a Turkish population. Anatomy 2017;11(1):30-36. 